\title{
Ag katkılı CdO ince filmlerinin sıcak püskürtme tekniği ile büyütülmesi ve yapısal incelemesi
}

\author{
Growth and structural characterization Ag doped CdO thin films by spray pyrolysis \\ technique
}

\section{Serdar AYDIN*1,a}

${ }^{1}$ Atatürk Üniversitesi, Bilgisayar Bilimleri Araştırma ve Uygulama Merkezi, 25240, Erzurum

\section{Öz}

Çalışmamızda Ag katkılanmış CdO ince filmlerinin (ITO) altlık üzerine sıcak püskürtme (Spray) tekniği ile altlıklar $400^{\circ} \mathrm{C}$ sabit sıcaklıkta iken büyütülme işlemi gerçekleştirilmiş ve üretilen ince filmlerin yapısal özellikleri araştırılmıştır. X-Işını Kırınımı (XRD) cihazı ile yapısal inceleme yapılmış, XRD sonuçlarından numunelerin polikristal kübik yapıda olduğu, tercihi yönelimlerinin katkı miktarının değişimiyle değişmeyip (111) düzlemi olduğu ve $23 \mathrm{~nm}$ civarında ortalama kristal boyutuna sahip olduğu görülmüştür. Taramalı Elektron Mikroskobu (SEM) ile ince filmlerin görüntüleri incelenmiş, Ag katkı oranı değişiminin yüzey morfolojisinde önemli bir değişime neden olmadığı görülmüştür.

Anahtar kelimeler: Ag katkı, CdO, Sıcak püskürtme

\begin{abstract}
In the study, Spray pyrolysis technic was used to grow Ag-doped CdO thin films on Indium Tin Oxide (ITO) substrates. Temperatures of ITO substrates were fixed at $400^{\circ} \mathrm{C}$. The structural and morphological properties of the thin films were investigated by X-Ray Diffraction (XRD) and Scanning Electron Microscope (SEM) devices. According to XRD results, the thin films have polycrystalline cubic structure and the average crystal sizes of thin films with Ag dopant are around $23 \mathrm{~nm}$. According to Scanning Electron Microscope (SEM) images, changing of Ag dopant ratio does not effects surface morphology of samples significantly.
\end{abstract}

Keywords: Ag dopant, CdO, Spray pyrolysis

*a Serdar AYDIN; serdar@ atauni.edu.tr, Tel: (0533) 5561662, orcid.org/0000-0003-4943-3272 


\section{Giriş}

Günümüzde hemen her alanda kullanmakta olduğumuz yarilietken aygitlar içerisinde oldukça önemli bir yere sahip olan ince filmlerin optik, elektrik yapısal incelemelerinin yapılması bilimsel açıdan oldukça önem arz etmektedir. Gün geçtikçe ilerleyen teknolojiyle birlikte, ince filmlerin kullanım alanları farklılık göstermektedir. İnce filmler, optoelektronik ve elektronik endüstrisinin ana unsurları arasında yer almaktadır. Son birkaç yılda, gelişmiş elektro-optik özellikleri sayesinde (saydam iletken oksit filmler) TCO'lar yaygin olarak kullanilan yarıiletken filmler arasinda kendilerine yer bulmuşlardır. TCO'lar optoelektronik cihazların üretiminde sahip oldukları önem nedeniyle araştırmacıların ilgisini cezbetmektedir. TCO'lardan biri olan $\mathrm{CdO}$ son yıllarda gaz sensör üretimi, güneş pili, fotodiyot uygulamaları, fototransistörler ve optoelektronik uygulamaları gibi uygulamalarda yüksek doğrusal refraktif indeks değeri, yüksek elektrik iletkenliği, taşıyıcı yoğunluğu ve elektromanyetik tayfin görünür bölgesinde yüksek optik geçirgenliği gibi bazı özelliklerinin sayesinde oldukça popüler olmuştur (Ali 2017; Abbas vd., 2018). Katk1lı ve katkısız CdO ince filmleri farklı tekniklerle oluşturulabilmektedir. Püskürtme (Ferro ve Rodriguez 1999), SILAR (Salunkhe ve Lokhande 2008; Güney ve İskenderoğlu 2017), termal buharlaşma (Dakhel ve Henari 2003), kimyasal buhar biriktirme (Li vd., 2001), sol-jel (Aksoy vd., 2009), darbeli lazer biriktirme (Gupta vd., 2009) teknikleri bu yöntemler arasında sayılabilir.

$\mathrm{Bu}$ çalışmada ekonomik, basit bir yöntem olması ve büyütülmesi planlanan ince filmlerin çözelti olarak püskürtülmesi, çözeltiye istenen tür ve miktarda katkı maddesi ile filmlerin fiziksel, elektriksel, optiksel v.b. birçok özelliklerini kolayca değiştirebiliyor olmamı sebebiyle Püskürtme tekniği seçilmiş ve gümüş (Ag) katkılı $\mathrm{CdO}$ ince filmlerinin İndiyum Kalay Oksit (ITO) altlı üzerine büyütülmesi başarılı olarak gerçekleştirilmiştir.

\section{Materyal ve metot}

B Spray Pyrolysis Yöntemi, kimyasal püskürtme tekniği olarak da bilinen bir yöntemdir. $\mathrm{Bu}$ teknikte, üretilmesi planlanan ince filmler için özel olarak hazırlanan kimyasal çözeltiler, hava veya azot gazı yardımiyla bernoulli prensibine uygun olarak atomize edilerek önceden 1sıtılmış altlıklar üzerine püskürtülür. Sonuç olarak sıcak altlık üzerine püskürtülerek gönderilen tanecikler film yüzeyine tutunur, tutunamayan tanecikler buharlaşarak gaz formunda ortamdan çekilir. $\mathrm{Bu}$ teknik kullanılarak üretilen filmler polikristal yapıda olmaktadır. Altlık sıcaklığı, büyütülen filmlerin yapısını ve özelliklerini doğrudan etkilediğinden oldukça önemlidir. Püskürtme hızı, püskürtme başlığı ile altlık arasındaki mesafe, başlangıç çözeltisinin etkisi ve sprey başlığının geometrisi gibi birçok parametre oluşturulacak kaplamanın özelliklerinin ayarlanmasında rol oynayan önemli faktörlerdir. Biz de bu çalışma öncesi yukarıdaki parametrelerden bazılarının denemeleri yapılmış ve uygun parametreler belirlenmiştir. Aşağıda laboratuvarımızda bulunan ve deneyleri gerçekleştirdiğimiz el yapımı püskürtme sisteminin şematik bir çizimi bulunmaktadır.

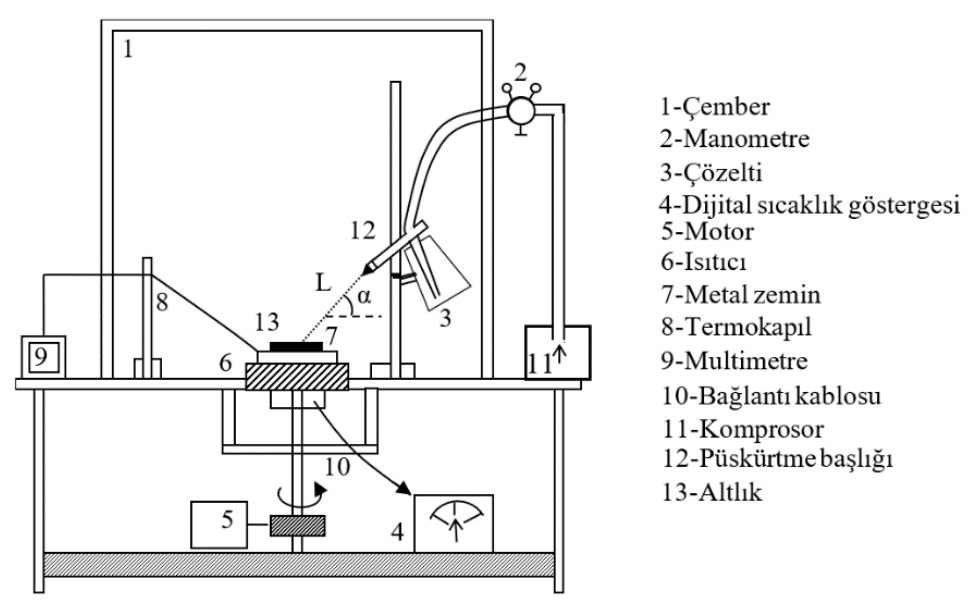

Şekil 1. Kimyasal Püskürtme Sistemi

Bu çalışmada öncelikli amacımız filmleri başarılı bir şekilde büyütebilmek ve sonrasında kristal ve morfolojik yapısını detaylı bir şekilde analiz etmektir. Bu yüzden de kristal yapısını olumlu bir şekilde etkilemesi için amorf bir altlik yerine kristal geometrisi $\mathrm{CdO}$ ya yakın olan bir polikristal 
altlık seçmektir. Bu sebepten ötürü yapılan çalışma da daha düzgün kristalleşmesine katk1 sağlayacak olan Indiyum kalay oksit (ITO) altlkklar kullanılmıştır. ITO altlık, büyütme işlemi gerçekleştirilmeden önce ultrasonik banyoda sirasiyla etanol ve sonrasinda deiyonize su (DI) içerisinde beşer dakika süreyle temizlenmiştir.

Gümüş (Ag) katkılı CdO ince ince filmlerin sprey tekniği ile büyütülmesi sürecinde püskürtme burnu ile altılık arasındaki mesafe $25 \mathrm{~cm}$ olarak belirlenmiştir. Nozzle sprey açısı $45^{\circ}$ olarak sabitlenerek ince filmlerin büyütülmesi sürecinde büyütme hızı $2,5 \mathrm{ml} / \mathrm{dk}$ olarak ayarlanmıştır. Her bir püskürtme için çözelti miktarının $100 \mathrm{ml}$ olacak şekilde hazırlanmıştır. Filtrelenmiş hava basıncı 11.5 bar olarak ayarlanmış ve taşıyıcı gaz olarak kullanılmıştır. Homojen bir film büyütebilmek için altlıkların üzerinde bulunduğu döner levhanın 20 rpm/dk hızla dönmesi sağlanmıştır. Cd kaynağ olarak $0,1 \mathrm{M}$ kadmiyum nitrat ve gümüş kaynağ 1 olarak $\% 0,1, \% 0,5, \% 1, \% 2$, ve $\% 3$ oranlarda $0,1 \mathrm{M}$ gümüş nitrat kullanılmıştır. Bu sayede $\mathrm{Ag}$ katkılı CdO filmleri ITO altlık üzerine ince film olarak büyütülmüştür. Numuneler en düşük katk1 miktarından başlayarak sırasıyla CdOA1 $(\% 0.1 \mathrm{Ag}), \quad \mathrm{CdOA} 2(\% 0.5 \mathrm{Ag})$, CdOA3(\%1Ag), CdOA4 $(\% 2 \mathrm{Ag}) \quad$ ve CdOA5 $(\% 3 \mathrm{Ag})$ olarak isimlendirilmiştir.

\subsection{Analizler}

\subsubsection{Fiziksel yöntemler}

Büyütülen ince filmlerin yapısal özellikleri incelemesinde X-ışını kırınım desenlerinden faydalanılmıştır. Panalytical Empyrean X-Ray difraktometresi aracılığı ile X-ışını kırınım deseni incelemesi, $\quad 20^{\circ} \leq 2 \Theta \geq 60^{\circ}$ açı aralığında, oda sicaklığında $0.05^{\circ}$ lik adım aralıklarında tarama yapılarak gerçekleştirilmiştir. Yüzey morfolojileri Zeiss-Sigma300 marka SEM ile görüntüleri alınarak incelendi.

\section{Bulgular}

Büyütülen İnce filmlerin, X-Işını kırınımı ölçümleri oda sıcaklığında alınmış ve Şekil 1 üzerinde gösterilmiştir. Şekil 1 incelendiğinde $\mathrm{Ag}$ katk1lı olarak büyütülen $\mathrm{CdO}$ ince filmlerinin, 20 ve 90 derece arasında gerçekleştirilen $2 \theta$ değeri taramas1 sonucunda 03-065-2908 ICSD kart numarasına göre kübik kristal yapıda olduğu tespit edilmiştir. Şekil 1'den görüldüğü gibi $\mathrm{Ag}$ katkılanmış CdO filmlerinin XRD açıları ve düzlemleri yaklaşık olarak sırasıyla; $33^{\circ}$ ve (111), $38^{\circ}$ ve $(200), 55^{\circ}$ ve $(220), 66^{\circ}$ ve (311) ile $69^{\circ}$ ve (222) şeklindedir. 03-065-2908 ICSD standard1 kart numarasına göre katkılama işlemi yapılmamış olan CdO filmlerinin XRD pikleri ile benzer olan ve Şekil 1'de yer almakta olan pik değerleri bize $\mathrm{Ag}$ katkılamanın $\mathrm{CdO}$ ince filmlerinin kristal yapısında değişikliğe neden olmadığ 1 ve mevcut yap1 ile iyi uyum sağladığını göstermektedir. Bu durum ise yapıda gümüş katkının oksitlenmesi sonucu oluşabilecek istenmeyen yapıların meydana gelmediğini sonucunu göstermektedir. Buna göre $\mathrm{Ag}$ katkılama hem ilave bir pik oluşturmamış hem de kübik kristal yapının bozulmasına neden olmamıştır. Ayrıca Tablo 1'den görüldüğü gibi $2 \theta$ değerlerinde dahi katkılama artması ile birlikte açı değerlerinde önemli bir değişim olmamıştır yani piklerde farklı miktardaki Ag katkısı ile kayma gerçekleşmemiştir.

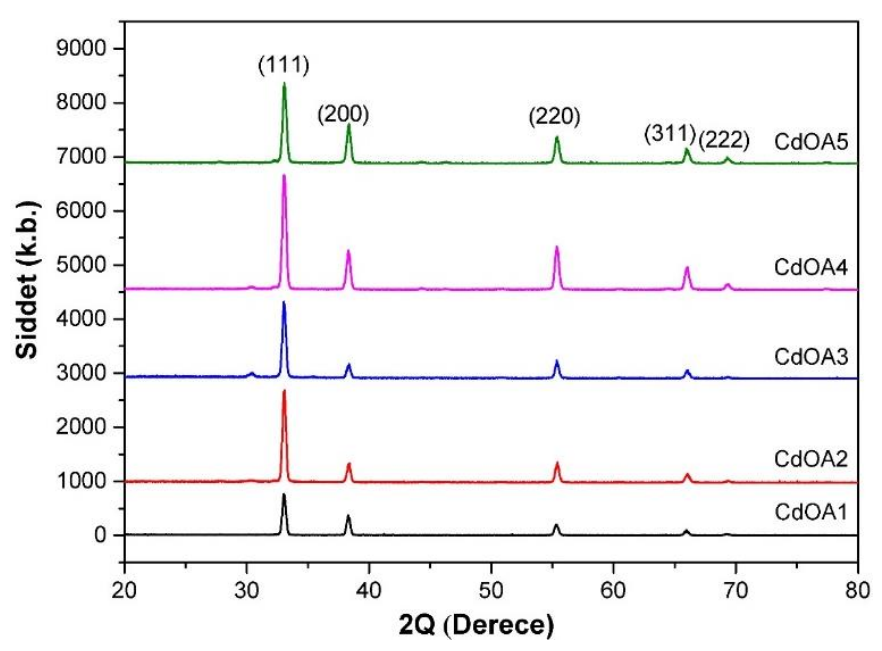

Şekil 2. Ag katkılı CdO ince filmlerinin XRD ölçümü grafiği

Baskın pikin olduğu (111) düzlemi kullanılarak numunelerin ortalama kristal boyutu (D) Denklem 1'de yer alan Scherer formülü kullanılarak hesaplanmıştır; 


$$
D=\frac{0.94 \lambda}{\beta \cos \theta}
$$

Bu denklemde $\mathrm{D}$, kristal boyutu, $\beta$ maksimumun yüksekliğin yarı genişliği (FWHM), $\theta$ yansıma veren düzlemlerin maksimum pikinin açı değeri ve $\lambda$, dalga boyu (0.15406 nm)'dir. Denklem 1 yardımı ile yapılan hesaplamalar sonucunda Ag katk1lı CdO ince filmlerinin kristal boyutları Tablo 1'de görüldüğü gibi baskın pik olan (111) düzlemi için ortalama kristal boyutu $23 \mathrm{~nm}$ bulunmuş ve Tablo 1 ve Şekil 2' de gösterilmiştir. Numunelerin tercihi yönelimi olan (111) düzlemine göre CdOA1, CdOA2 ve CdOA3 ün kristal boyutu $23 \mathrm{~nm}$ iken CdOA4 $20 \mathrm{~nm}$ ve CdOA5 için ise $22 \mathrm{~nm}$ olduğu görülmektedir. Böylece Ag katkısı ile $\mathrm{CdO}$ ince filmlerinin kristal yapısında ciddi değişim oluşmadığı düşünülebilir. İskenderoğlu ve Güney'in 2018 yılında yaptıkları çalışmada Ag katkılı CdO filmler cam altlık üzerine başka bir yöntem kullanarak filmleri büyütmüşler onlarda ortalama olarak filmlerin tanecik boyutlarını $24 \mathrm{~nm}$ olarak bulmuşlardır. Buradan hareketle farklı tekniklerle büyütülen filmlerin tanecik boyutunda önemli bir katkısının olmadığını söyleyebiliriz (İskenderoğlu ve Güney, 2018).

Tablo 1'de gösterilmiş olan büyütülen ince filmlerin düzlemler arası uzaklığı (d) Denklem 2'de gösterilen Bragg kanunu kullanılarak hesaplanmıştır.

$$
n \lambda=2 d \sin \theta
$$

Hesaplamalar sonucunda çıkan d değerlerinin 03065-2908 numaralı ICSD standart kartı ile benzerlik gösterdiği görülmüştür. $\mathrm{Bu}$ sonuçlar püskürtme tekniği ile büyütülen $\mathrm{Ag}$ katkılı $\mathrm{CdO}$ numunelerinin literatürde yer alan diğer çalışmalarda yer alan değerlerle uyuşmakta olduğunu ve üretilen ince filmlerin yüksek kalitede olduğu anlaşılmaktadır.

\begin{tabular}{|c|c|c|c|c|c|c|c|c|c|c|c|c|c|c|c|c|}
\hline $\begin{array}{l}\text { Numune } \\
\text { Ad1 }\end{array}$ & Düzlem & $2 \theta$ & FWHM & Io & Şiddet & I & I/Io & Tc & $\mathrm{D}$ & $\delta$ & $\varepsilon$ & $\mathrm{d}_{0}$ & d & $\mathrm{a}$ & aavg & V \\
\hline & (hkl) & $\left({ }^{\circ}\right)$ & $\left({ }^{0}\right)$ & & & & & & $(\mathrm{nm})$ & $\times 10^{12}$ & & $(\AA)$ & $(\AA)$ & $(\AA)$ & $(\AA)$ & $(\AA)^{3}$ \\
\hline & (111) & 33.01 & 0.333 & 100 & 751 & 100 & 1.00 & 1.71 & 23 & 1.91 & 0.00409 & 2.712 & 2.711 & 4.69625 & \multirow{5}{*}{4.695} & \multirow{5}{*}{103.510} \\
\hline & $(200)$ & 38.30 & 0.323 & 86 & 374 & 50 & 0.58 & 0.99 & 23 & 1.85 & 0.00398 & 2.349 & 2.348 & 4.69634 & & \\
\hline \multirow[t]{5}{*}{$\mathrm{CdAg} 1$} & $(220)$ & 55.27 & 0.344 & 48 & 198 & 26 & 0.55 & 0.94 & 20 & 2.39 & 0.00477 & 1.661 & 1.661 & 4.69720 & & \\
\hline & $(311)$ & 65.96 & 0.388 & 31.2 & 100 & 13 & 0.43 & 0.73 & 17 & 3.39 & 0.00604 & 1.416 & 1.415 & 4.69333 & & \\
\hline & $(222)$ & 69.30 & 0.339 & 13.6 & 38 & 5 & 0.37 & 0.64 & 19 & 2.69 & 0.00550 & 1.355 & 1.355 & 4.69324 & & \\
\hline & $(111)$ & 33.05 & 0.336 & 100 & 1683 & 100 & 1.00 & 2.29 & 23 & 1.95 & 0.00413 & 2.712 & 2.708 & 4.69072 & \multirow{5}{*}{4.689} & \multirow{5}{*}{103.093} \\
\hline & $(200)$ & 38.33 & 0.300 & 86 & 340 & 20 & 0.23 & 0.54 & 25 & 1.60 & 0.00370 & 2.349 & 2.346 & 4.69281 & & \\
\hline \multirow[t]{5}{*}{$\mathrm{CdAg} 2$} & $(220)$ & 55.44 & 0.303 & 48 & 378 & 22 & 0.47 & 1.07 & 23 & 1.86 & 0.00421 & 1.661 & 1.656 & 4.68393 & & \\
\hline & $(311)$ & 66.05 & 0.391 & 31.2 & 168 & 10 & 0.32 & 0.73 & 17 & 3.45 & 0.00610 & 1.416 & 1.413 & 4.68766 & & \\
\hline & $(222)$ & 69.36 & 0.278 & 13.6 & 37 & 2 & 0.16 & 0.37 & 23 & 1.81 & 0.00451 & 1.355 & 1.354 & 4.68969 & & \\
\hline & $(111)$ & 33.05 & 0.332 & 100 & 1432 & 100 & 1.00 & 2.23 & 23 & 1.90 & 0.00408 & 2.712 & 2.708 & 4.69072 & \multirow{5}{*}{4.689} & \multirow{5}{*}{103.097} \\
\hline & $(200)$ & 38.36 & 0.330 & 86 & 275 & 19 & 0.22 & 0.50 & 23 & 1.94 & 0.00407 & 2.349 & 2.345 & 4.68927 & & \\
\hline \multirow[t]{5}{*}{$\mathrm{CdAg} 3$} & $(220)$ & 55.36 & 0.323 & 48 & 336 & 23 & 0.49 & 1.09 & 22 & 2.11 & 0.00448 & 1.661 & 1.658 & 4.69017 & & \\
\hline & (311) & 66.07 & 0.390 & 31.2 & 157 & 11 & 0.35 & 0.79 & 17 & 3.43 & 0.00608 & 1.416 & 1.413 & 4.68640 & & \\
\hline & $(222)$ & 69.38 & 0.264 & 13.6 & 34 & 2 & 0.17 & 0.39 & 25 & 1.63 & 0.00429 & 1.355 & 1.353 & 4.68851 & & \\
\hline & $(111)$ & 33.05 & 0.376 & 100 & 2123 & 100 & 1.00 & 1.55 & 20 & 2.44 & 0.00462 & 2.712 & 2.708 & 4.69072 & \multirow{5}{*}{4.690} & \multirow{5}{*}{103.152} \\
\hline & $(200)$ & 38.32 & 0.390 & 86 & 734 & 35 & 0.40 & 0.62 & 19 & 2.70 & 0.00481 & 2.349 & 2.347 & 4.69399 & & \\
\hline \multirow[t]{5}{*}{$\mathrm{CdAg} 4$} & $(220)$ & 55.36 & 0.390 & 48 & 801 & 38 & 0.79 & 1.22 & 18 & 3.08 & 0.00541 & 1.661 & 1.658 & 4.69017 & & \\
\hline & $(311)$ & 66.05 & 0.433 & 31.2 & 429 & 20 & 0.65 & 1.00 & 15 & 4.23 & 0.00675 & 1.416 & 1.413 & 4.68766 & & \\
\hline & $(222)$ & 69.41 & 0.418 & 13.6 & 114 & 5 & 0.39 & 0.61 & 16 & 4.10 & 0.00679 & 1.355 & 1.353 & 4.68673 & & \\
\hline & (111) & 33.06 & 0.342 & 100 & 1484 & 100 & 1.00 & 1.46 & 22 & 2.02 & 0.00420 & 2.712 & 2.707 & 4.68934 & \multirow{5}{*}{4.690} & \multirow{5}{*}{103.165} \\
\hline & $(200)$ & 38.37 & 0.394 & 86 & 730 & 49 & 0.57 & 0.83 & 19 & 2.76 & 0.00486 & 2.349 & 2.344 & 4.68810 & & \\
\hline \multirow[t]{3}{*}{ CdAg5 } & $(220)$ & 55.41 & 0.385 & 48 & 497 & 33 & 0.70 & 1.02 & 18 & 3.00 & 0.00534 & 1.661 & 1.657 & 4.68627 & & \\
\hline & $(311)$ & 65.97 & 0.354 & 31.2 & 275 & 19 & 0.59 & 0.87 & 19 & 2.82 & 0.00552 & 1.416 & 1.415 & 4.69270 & & \\
\hline & $(222)$ & 69.29 & 0.360 & 13.6 & 114 & 8 & 0.56 & 0.82 & 18 & 3.04 & 0.00584 & 1.355 & 1.355 & 4.69383 & & \\
\hline
\end{tabular}

Tablo 1. Ag katkılı CdO filmlerin hkl, 2ө, FWHM, I, TC, D, d, a, V, değerleri 
Ag katk11 $\mathrm{CdO}$ ince filmlerin texture coefficient (TC(hkl)) değerleri XRD sonuçlarından aşağıdaki formül kullanarak hesaplanmış ve tablo 1 de verilmiştir.

$T C(h k l)=\frac{I(h k l) / I_{0}(h k l)}{N^{-1} \sum_{N} I(h k l) / I_{0}(h k l)}$

Bu denklemde I (hkl) değeri ölçülen pik şiddeti, I0 (hkl) ise ICSD data karttan alınan standart şiddet ve $\mathrm{N}$ is yansıma veren düzlem sayısıdır [1]. Ag katkısının artmasıyla numunelerin tercihi yönelimi değişmemekte ve (111) olarak görülmektedir. Güney ve İskenderoğlunun 2021 yılında yaptıkları çalışmada da $\mathrm{Ag}$ katkılı $\mathrm{CdO}$ filmler optik cam üzerine büyütülmüş ve tercihi yönelimlerinin (200) olduğunu bulmuşlardır (Güney ve İskenderoğlu, 2021). Buradan hareketle altlık seçiminin tercihi yönelimi belirleme de önemli bir parametre olduğunu söyleyebiliriz. Ayrıca Aşağıdaki Şekil 3 'de de görüldüğü üzere bütün ince filmlerin tercihi yönelimi olan (111) düzleminin TC değeri olması gerektiği gibi 1 den büyüktür.

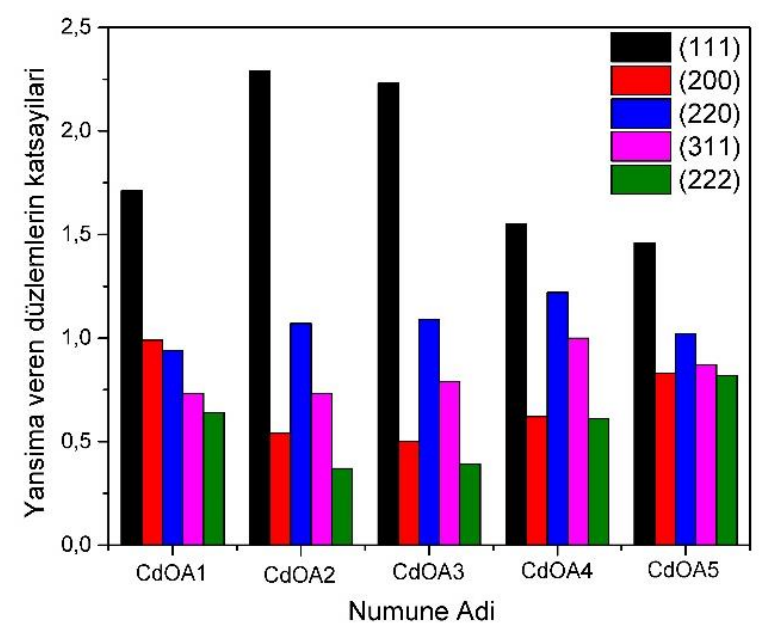

Şekil 3. Ag katkılı CdO filmlerin TC değişimi

Numunelerin önemli kristal parametlerinden biri olan ince filmlerin düzlemler arası mesafesi (d) Bragg yasası ile hesaplanmış ve Tablo 1'de gösterilmiştir. Table 1 de hesaplanan d değerleri ile ICSD kart numaras1 03-065-2908 olan standart karttaki değerleri ile karşıllaştırılmıştır. Kübik CdO yapısının Latis sabiti (a) ve birim hücrenin hacmi (V) aşağıda verilen formuller yardımıyla hesaplanmıştır.

$d=\frac{a}{\sqrt{\left(h^{2}+k^{2}+l^{2}\right)}}$

$V=a^{3}$
Tablo 1'de görülebildği üzere, a' nın ortalama değerleri sirasiyla $4.695,4.689,4.689,4.690$ ve $4.690 \AA$ and $V^{\prime}$ nin ortalama değerleri 103.510, $103.093,103.097,103.152$ ve $103.162 \AA 3$ olarak hesaplanmıştır. $\mathrm{Bu}$ değerler, ICSD kartındaki kübik $\mathrm{CdO}$ yapıları için standart verilerle uyumludur. Bütün bu hesaplamalar $\mathrm{CdO}$ in başarılı bir şekilde büyütüldüğünü de göstermektedir.

Filmlerin dislokasyon yoğunluk $(\delta)$ değerleri ile mikrozorlanma $(\varepsilon)$ değerleri aşağıdaki eşitlikler ile hesaplanmış ve Tablo 1 de paylaşı1mıştır.

$$
\begin{aligned}
\delta & =\frac{1}{D^{2}} \\
\varepsilon & =\left(\frac{1}{\sin \theta}\right)\left[\left(\frac{\lambda}{D}\right)-(\beta \cos \theta)\right]
\end{aligned}
$$

bu denklemde $\mathrm{D}$ kristal boyutu, $\beta$ radyan olarak yansıma veren düzlemin pik şiddetinin maksimum yüksekliğinin yarısının genişliği ve $\lambda$ ise $X$ ışınının dalga boyudur $(\lambda=1.5418 \AA)$.

Tablo 1'i incelediğimizde en düşük dislokasyon yoğunluğu değerleri için CdOA1 ve $\mathrm{CdOA} 2$ filmlerinde (200) düzlemine ait olduğu CdOA3 filmi için (222) düzleminde ve CdOA4 ve CdOA5 için ise (111) düzlemlerine ait olduğu görülmektedir. Bu sonuçlar, farklı Ag katkısının CdO'nun kristallik derecesinde önemli bir farklılaşmaya neden olmadığını da gösterir.
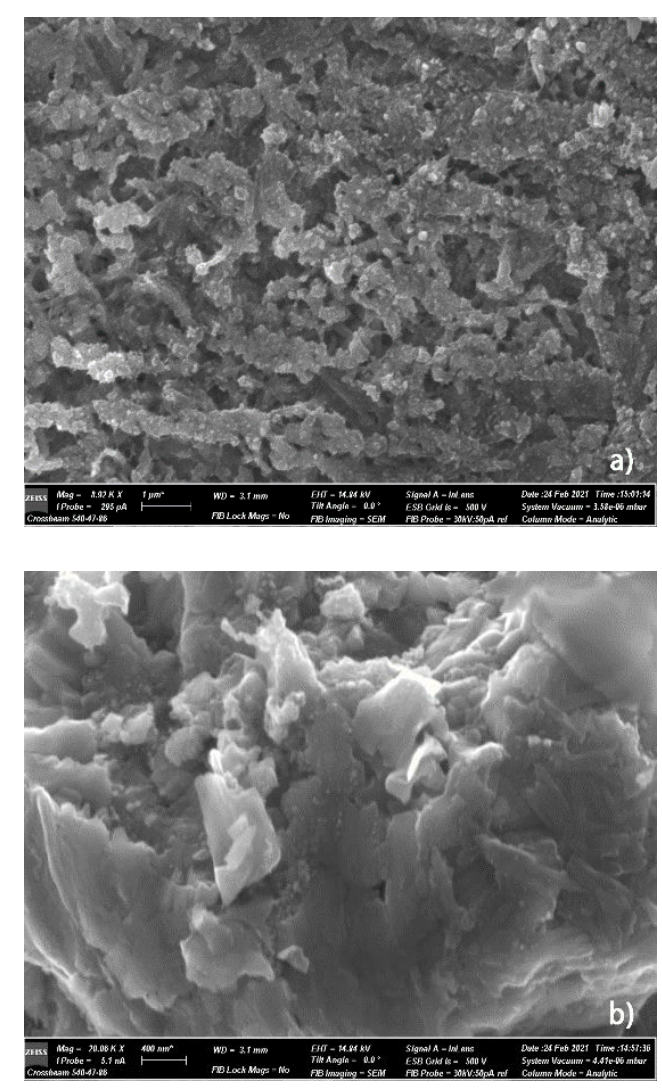

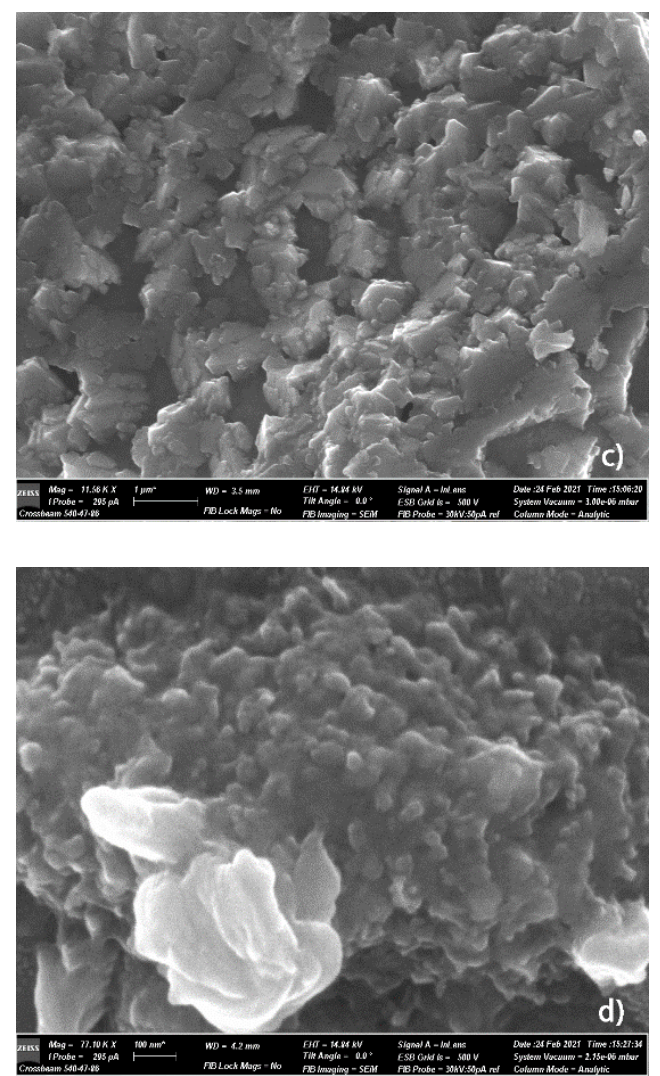

Şekil 4. a) ve b) $\mathrm{CdOA} 1$, c) ve d) $\mathrm{CdOA} 5$ numunelerinin SEM görüntüleri

İnce filmlerin birçok özelliğinde önemli etken olan SEM görüntüleri, Ag katkı miktarının değişiminin etkisini gözlemlemek için alınmış ve Şekil 4'de gösterilmiştir. Yüzey morfolojisinin $\mathrm{Ag}$ katk1 oranına göre değişimini araştırmak için farklı büyütmelerdeki $\mathrm{CdO}$ : $\mathrm{Ag}$ ince filmlerin SEM görüntüleri analiz edilmiş ve en az katkı miktarı ile en fazla katkı miktarının görüntüleri Şekil 4'de gösterilmektedir. Şekil 4'de Ag katkısı arttıkça numunelerde yüzey morfolojilerinin değişiminde de XRD sonuçlarını doğrulayan şekilde önemli bir değişiklik olmadığ 4'de Ag katkılanmış ince filmlerin XRD verilerine göre $\mathrm{CdO}$ yapısı içerisinde $\mathrm{Ag}$ miktarının değişimine rağmen kübik yapılarının oluştuğu fakat SEM görüntülerinde bu kübik yapılar tetragonal bir kristal yapisına sahip olan ito altlıklar üzerinde bir araya geldiklerinden köşeli yapıları oluşturduğu gözlenmektedir. Ayrıca bu yapıların da Ag katkısı ile birlikte daha küçük parçalara ayrıldığg düşünülmektedir.

\section{Tartışma ve sonuçlar}

$\mathrm{Bu}$ çalışmamızda gümüş $(\mathrm{Ag})$ katkılı $\mathrm{CdO}$ filmleri püskürtme tekniği ile ince film olarak başarılı bir şekilde büyütülmüş, XRD ve SEM aracıllğı ile morfolojik ve yapısal özellikleri incelenmiştir. Sonuçlar analiz edildiğinde püskürtme tekniği ile büyütülen numuneler kübik kristal yapıda olduğu ve yüzey morfolojisinin de $\mathrm{Ag}$ katkı miktarının değişimi ile önemli ölçüde değişmediği sergilenmiştir. Ayrıca XRD verilerinden yaptığımız hesaplamalarla numuneye ait birçok özelliğin detaylı olarak incelenmesi sağlanmış ve katkı miktarının değişiminin etkisi incelenmiştir.

\section{Kaynaklar}

Aksoy, S., Caglar, Y., Ilican, S. and Caglar, M. (2009). Effect of heat treatment on physical properties of $\mathrm{CdO}$ films deposited by sol-gel method. International Journal of Hydrogen Energy, 34(12), 5191-5195, https://doi.org/10.1016/j.ijhydene.2008.09.057

Ali, O. (2017). Study of Structural, morphological and optical properties of pure $\mathrm{CdO}$ and $\mathrm{Ag}$ : $\mathrm{CdO}$ doped thin films on glass substrates with high relatively $\mathrm{Ag}$ concentrations $(2.5 \%, 5 \% 10 \%$ and $15 \%)$ prepared by Sol-Gel method, Journal of Applied Physics, 9, 1-8. https://doi.org/10.9790/4861-0901030108

Dakhel, A. A. and Henari, F. Z. (2003). Optical characterization of thermally evaporated thin CdO films. Crystal Research and Technology, 38(11), 979-985, https://doi.org/10.1002/crat.200310124

Ferro, R., Rodriguez. and J. A. (1999). Some physical properties of F-doped $\mathrm{CdO}$ thin films deposited by spray pyrolysis, Thin solid films, 347(1-2), 295-298.

Gupta, R. K., Ghosh, K., Patel, R. and Kahol, P. K. (2009). Highly conducting and transparent Tidoped CdO films by pulsed laser deposition, Applied Surface Science, 255(12), 6252-6255, https://doi.org/10.1016/j.apsusc.2009.01.091

Güney, H. ve İskenderoğlu, D. (2017). SILAR yöntemi ile büyütülen katkısız ve Zn katkılı CdO yar iletken ince filmlerinin yapisal, optik ve morfolojik özelliklerinin incelenmesi, SAÜ Fen Bilimleri Enstitüsü Dergisi, 21(6), 1-1. https://doi.org/10.16984/saufenbilder.312291

Güney, H. and İskenderoğlu, D. (2021). CdO: Ag semiconductor nanowires grown by spray method, Journal of Alloys and Compounds, 865 158924 , https://doi.org/10.1016/j.jallcom.2021.158924

İskenderoğlu, D. ve Güney H. (2018). CdO: Ag ince filmlerinin SILAR tekniği ile büyütülmesi ve karakterizasyonu, Gümüşhane Üniversitesi Fen Bilimleri Enstitüsü Dergisi (2019), 9 (1), 128135 , https://doi.org/10.17714/gumusfenbil.360478 
Li, X., Young, D. L., Moutinho, H., Yan, Y., Narayanswamy, C., Gessert, T. A. and Coutts, T. J. (2001). Properties of CdO thin films produced by chemical vapor deposition, Electrochemical Solid-State Letters, 4(6), C43-C46.
Salunkhe, R. R. and Lokhande, C. D. (2008). Effect of film thickness on liquefied petroleum gas (LPG) sensing properties of SILAR deposited CdO thin films, Sensors and Actuators B: Chemical, 129(1),

345-351, https://doi.org/10.1016/j.snb.2007.08.035 